\title{
IMPROVING PERFORMANCE AND SERVICE LIFE OF RAIL VEHICLES COMPONENTS BY TWIN WIRE ARC SPRAYING
}

\author{
${ }^{1}$ Petra ŠULCOVÁ, ${ }^{2}$ Marek VOSTŘÁK, ${ }^{3}$ Jakub ANTOŠ, ${ }^{4}$ Kateřina LENCOVÁ \\ ${ }^{1}$ Research and Testing Institute Plzen̆, PIzeň, Czech Republic, EU, sulcova@vzuplzen.cz \\ ${ }^{2}$ Research and Testing Institute Plzeň, Plzeň, Czech Republic, EU, votrak@vzuplzen.cz \\ ${ }^{3}$ Research and Testing Institute Plzeň, Plzeň, Czech Republic, EU, antos@vzuplzen.cz \\ ${ }^{4}$ Research and Testing Institute Plzen̆, Plzeň, Czech Republic, EU, lencova@vzuplzen.cz
}

https://doi.org/10.37904/metal.2020.3570

\begin{abstract}
The components of rail vehicles are strained by a number of sources, whether operational, natural, or effects caused by passengers. For protection against these influences, the number of types of surface protection is frequently used. The project called "Increasing of resistance of rail vehicles components by the means of modern thermal spraying technologies" deals with improving the performance and service life of rail vehicle components by thermal spraying. In the project, more than ten components are selected for coating by different material sprayed by different methods of thermal spraying. This paper is focused on coating made by Twin Wire Arc Spraying. Three materials of coating sprayed by TWAS were tested and their mechanical properties were evaluated in this paper. These materials are pure molybdenum, $\mathrm{Fe} 13 \mathrm{Cr}$, and $\mathrm{Zn} 15 \mathrm{Al}$. The Ball on Flat, Dry Sand/Rubber wheel Test, and Erosion Wear Resistance Test were done. The molybdenum coating showed very good sliding properties. This material can find its application for rolling components such as rollers, or rollers carriers. The $\mathrm{Fe} 13 \mathrm{Cr}$ and $\mathrm{Zn} 15 \mathrm{Al}$ coatings showed a very good erosion resistance. The $\mathrm{Zn} 15 \mathrm{Al}$ had even a better erosion resistance than Fe13Cr. Both of these materials can be used, where this type of wear resistance is required, for example for walkable footplates. The $\mathrm{Fe} 13 \mathrm{Cr}$ had also a very good abrasive resistance in contrast with Zn15Al, which can't be recommended for application where abrasion resistance is required. The spraying of real components is also shortly presented in this paper.
\end{abstract}

Keywords: Thermal spraying, twin wire arc spraying, rail vehicles components, abrasion resistance, erosion resistance, sliding properties

\section{INTRODUCTION}

Rail vehicles are one of the most commonly used means of transport applied for transportation of people as well as the transportation of cargo. Their utilization is found in urban, intrastate, and also in international transport. In addition to conventional operating wear, the components of rail vehicles are also strained by a number of external sources those being wear by passengers, or degradation by natural influences like water, humidity, temperature changes, ice, snow, UV radiation, deicing and cleaning agents, but also small objects (sand, stones...). To reduce the influence of these sources, the number of types of surface protection is frequently used. The often-used protections are hot dip galvanizing, tinning, non-electrolytically applied zinc micro-lamella coating, or electrolytic zinc coating. In the project "Increasing of resistance of rail vehicles components by the means of modern thermal spraying technologies" the new type of surface protection of some selected components applied by thermal spraying is searched. The project is being solved by the corporation of Škoda Transportation and Research and Testing Institute Pilsen. Škoda Transportation is a prominent European producer of rail vehicles and Research and Testing Institute Pilsen has been engaged in 
thermal spraying for more than 30 years, so the connection of these two companies is promising auspicious results.

In this project, the different types of coatings sprayed by various methods of thermal spraying (TWAS, FS, HVOF, and APS) for dissimilar components are being researched. This paper is focused on coatings made by Twin Wire Arc Spraying (TWAS). The materials of coatings that are being tested are pure molybdenum, $\mathrm{Fe} 13 \mathrm{Cr}$, and $\mathrm{Zn} 15 \mathrm{Al}$. The numbers of mechanical properties for optimized coatings, such erosion and abrasion resistance, or sliding properties are evaluated. The coating of real components is also presented in this paper.

The common principle of thermal spraying is the melting of the feedstock by a heat source and then accelerating the melted particles it towards the coated surface where it is embedded by mechanical interlocking. Thanks to that, the affection of the substrate by heating is minimal. The adhesion of this bond is however not as strong as the bond made by diffusion emerging in other methods of coating. The feedstock is either in powdered or wired form. The heat source can be electrical (arc, plasma), or chemical (flame, combustion). The structure of thermal sprayed coatings is usually laminar, heterogeneous with a certain content of oxides, pores, and other impurities. The characteristics of these coatings are for example good wear resistance, good corrosion resistance, better sliding properties, thermal insulation, or an electrically resistive and it depends on the feedstock materials, used methods of spraying and spraying parameters. [1]

In the case of Twin Wire Arc Spraying, the feedstock is in the form of wires, the heat source is electric arc regulated by values of current and voltage and the melted particles are accelerated by compressed air flow. Compared to the coatings made by methods HVOF and APS, the coatings made by TWAS have usually a higher content of pores and oxides and lower adhesion, but they are also significantly cheaper, and easier to spray. The mobility of the device and the possibility of spraying by hand are also distinct advantages of this method. [1]

\section{MATERIALS}

Three materials for different applications were tested. Molybdenum coating is widely used as a surface treatment, offering high wear and scuffing resistance. This coating also has prominent sliding properties and therefore synchronizer rings, selector forks, and piston rings can be found among the typical applications. The Fe13Cr could be used for all purposes of general engineering applications, like restoring or build-up. This coating has low shrinkage, excellent wear properties, and fair corrosion resistance. Zn15Al has preeminent corrosion resistance in atmosphere and immersion in either fresh or salt water. This coating often has better corrosion resistance than either pure zinc or aluminum, by combining the advantages of both materials. Typical applications of this coating are large steel or iron structures such as roadway barriers, bridges, offshore structures, posts and poles, and marine structures $[2,3]$.

\section{EXPERIMENT}

The sliding properties were tested on molybdenum coating according to norm ASTM G-133 Ball on Flat linear oscillating test. The parameters of the test were: Dry contact without lubrication, counterpart: the $\mathrm{Cr}$-steel ball $6 \mathrm{~mm}$, normal force: $25 \mathrm{~N}$, length of track: $10 \mathrm{~mm}$, cycling frequency: $5 \mathrm{~Hz}$, and time of test: $1000 \mathrm{~s}$. Three samples under these conditions were tested. Progress of the coefficient of friction in relation to the testing time and the wear behavior were evaluated. The wear behavior was represented by the wear coefficient $K$ $\left[\mathrm{mm}^{3} / \mathrm{Nm}\right]$ which was determined from the wear track profile measurement. The resistance of abrasion and erosion wear was tested for materials Fe13Cr and Zn15Al. For the testing of abrasion resistance, the Dry Sand/Rubber Wheel Test according to norm ASTM G-65 was used. In this test, dry sand is steadily brought between the sample of coating and rotating rubber wheel, which is pressed to the sample by constant force $(22 N)$. Three samples were tested for each material. The abrasive medium was white corundum with grain size F70. The overall wheel track is $718 \mathrm{~m}$ and it is divided into five congruous cycles. The cumulative volume 
loss from the coating per wheel track is evaluated. In the erosion resistance test, the erosive medium is centrifugally accelerated towards the samples, on which it acts with its kinetic energy. The erosion medium impacts the samples at different angles $\left(90^{\circ}, 60^{\circ}, 45^{\circ}, 30^{\circ}\right.$ and $\left.15^{\circ}\right)$. For each angle, two samples of each material were tested. Three cycles were done for each sample. The duration of the cycle was 2 minutes. The average volume loss per one cycle was evaluated [4-8].

\section{COATINGS OF REAL COMPONENTS}

In the project, the feasibility of the thermal sprayed coatings on real components is also tested. For this test, more than ten components sprayed by different materials and different technologies were chosen. In this paper, the spraying of walkable footplate is described for illustration. The walkable footplate is mounted on the front of the locomotive. It is affected by external influences such as salt, water, rain, and aerodynamics forces. Because this component is walkable, the surface can be worn also by stones and sand from people's shoe soles. The material of the coating has to be resistant to corrosion in the atmospheric and slightly aggressive environment (salt) and also has to have adequate wear resistance. Based on these requirements materials Fe13Cr and Zn15Al sprayed by TWAS were chosen. The difficulty of spraying of this component is in the shape complexity, the small thickness of the component, and the requirement to spray all surfaces. The sprayed footplates are shown in Figure 1. Because of the shape complexity and a small number of sprayed components, spraying by hand was used. One of the main evaluated factors was the affection of the geometry of the component by thermal spraying. Therefore different footplate thicknesses were tested. During the spraying of footplates with a higher thickness $(5 \mathrm{~mm})$, the geometry was not affected, but if the footplate with a smaller thickness $(2.5 \mathrm{~mm})$ was sprayed, the geometry was affected in the case when Fe13Cr was used. The temperature during spraying $\mathrm{Fe} 13 \mathrm{Cr}$ was about $120^{\circ} \mathrm{C}$ and if the $\mathrm{Zn} 15 \mathrm{Al}$ was sprayed, the temperature was about $40^{\circ} \mathrm{C}$. However, the geometry of the footplate with a small thickness was distinctly affected by blasting before the spraying. The blasting is however necessary surface preparation for thermal spraying.
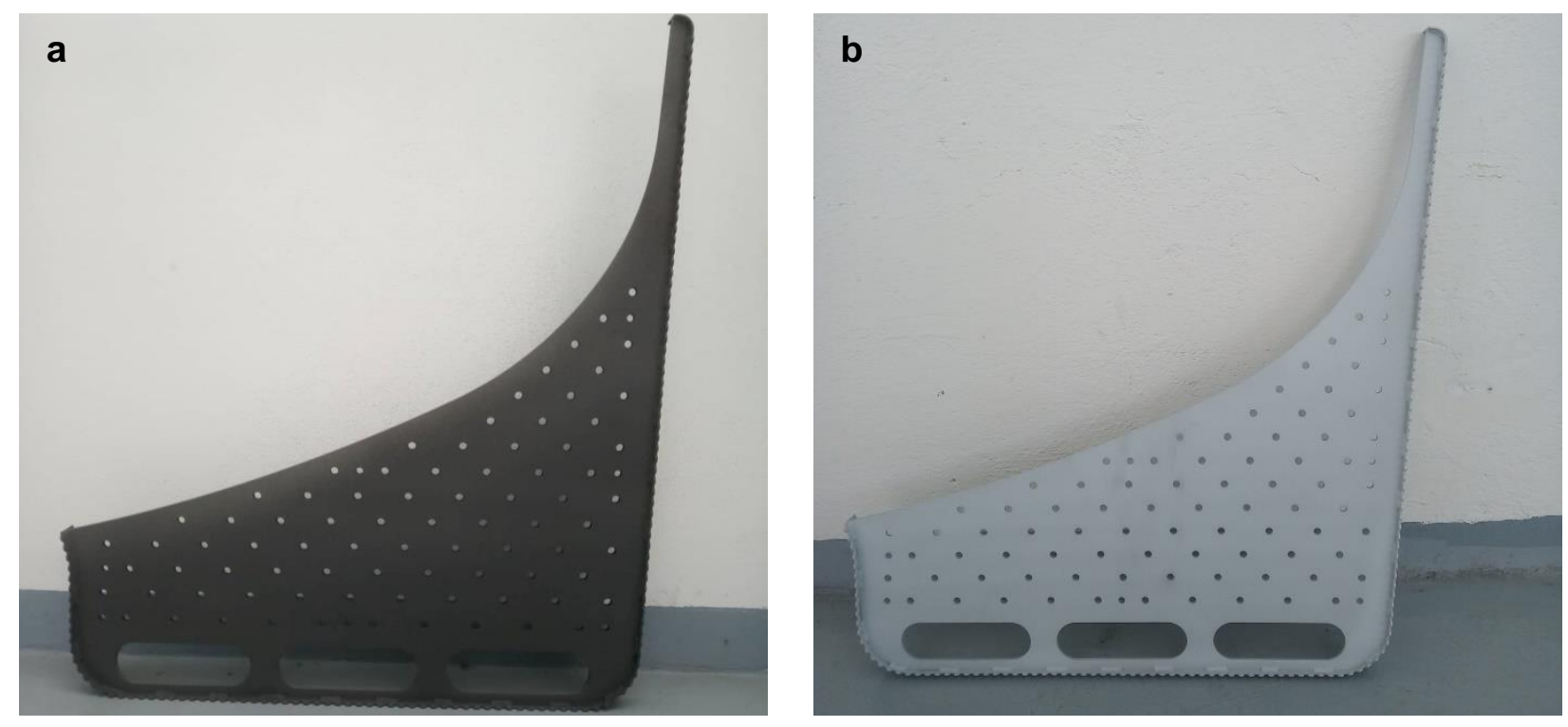

Figure 1 Walkable footplates sprayed by a) Fe13Cr; b) Zn15Al

\section{RESULTS}

Microstructures of all three evaluated materials are shown in Figure 2. All three samples have porosity typical for spraying by TWAS. On the other hand, all three coatings are without crack and other defects reducing the quality of the coatings. Because the chemical compositions of these coatings are very different, the 
microstructure of each coating also looks dissimilar. The molybdenum coating has a variable microstructure across the cross sections. In the lower part of the coatings, there is lower porosity and inter-splat decohesion, compare to the upper part. More about this phenomenon is written in the report [9]. The microstructure of $\mathrm{Zn15Al}$ is homogenous without visible boundaries of splats and without oxides. In the Fe13Cr coating, there is a higher amount of oxides on the boundaries of splats caused by the reaction of $\mathrm{Cr}$ with air during spraying.
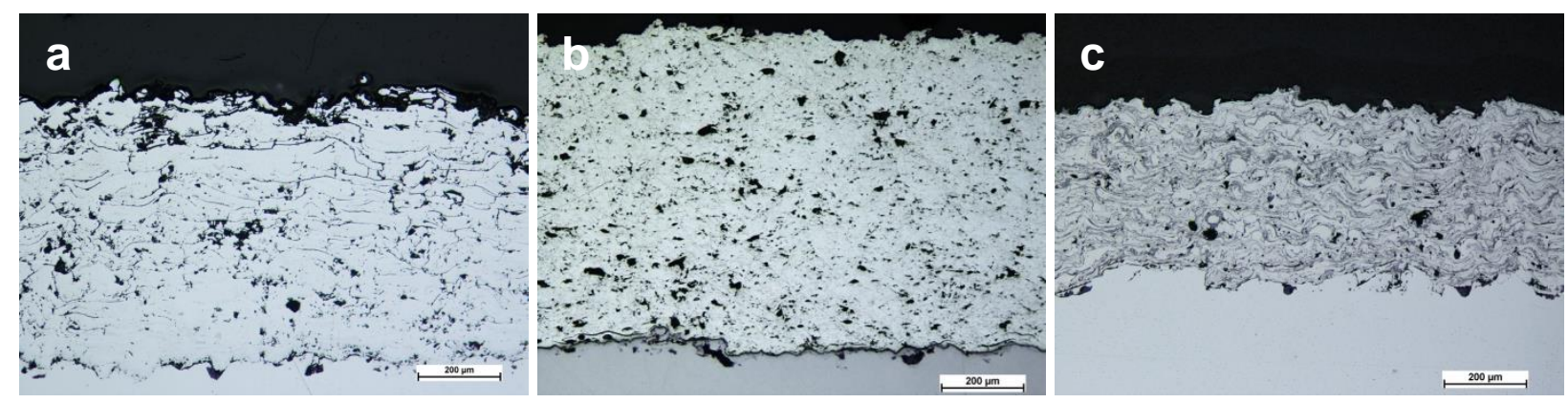

Figure 2 Microstructure of a) molybdenum coating; b) Zn15Al coating; c) Fe13Cr coating

The result of the Ball on Flat test on molybdenum coating is shown in Figure 3. All three samples showed the same progress of coefficient of friction in time. The dependence showed two stages of dry friction contact. In the first initial stage, the coefficient of friction was about $0.78 \pm 0.025$ and after some time, the value of COF fell down to $0.69 \pm 0.015$ and was constant until the end of the test. The time of the initial stage was a little bit different for each sample and ranged between 360 and $580 \mathrm{~s}$. The wear coefficient for this coating is $\mathrm{K}=2.06^{*} 10-4 \pm 2.8^{*} 10-5 \mathrm{~mm}^{3} / \mathrm{Nm}$. These good sliding properties confirm the suitability of molybdenum coating for rolling components such as rollers, or rollers carriers.

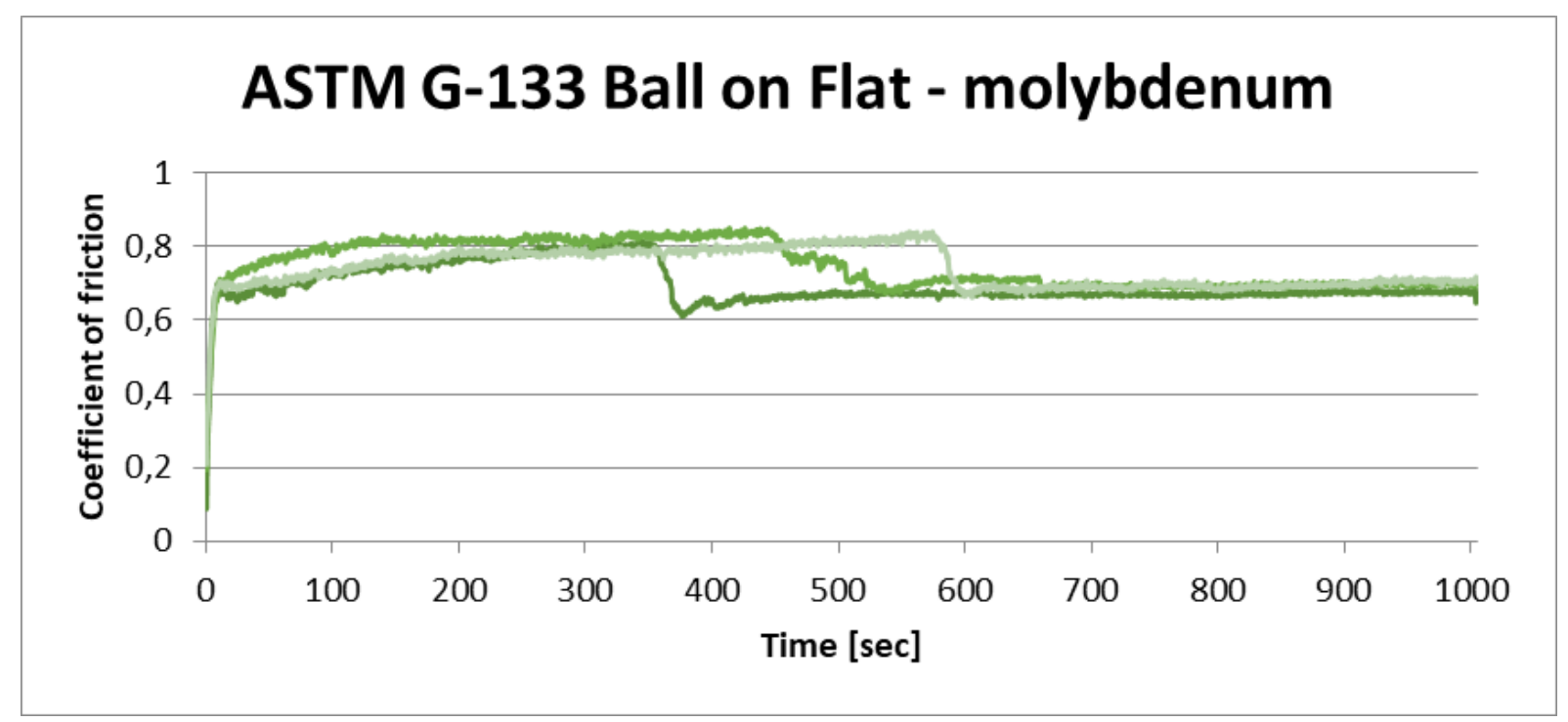

Figure 3 Results of Ball on Flat test

The results of the Dry Sand/Rubber Wheel Test for Fe13Cr and Zn15Al coatings are shown in Figure 4. The abrasive resistance of $\mathrm{Fe} 13 \mathrm{Cr}$ coating was suitable for most applications. The cumulative volume loss per wheel track of $718 \mathrm{~m}$ was $52.8 \pm 0.9 \mathrm{~mm}^{3}$. The test of abrasion resistance for $\mathrm{Zn} 15 \mathrm{Al}$ had to be stopped after three cycles because the coating was worn out. The cumulative volume loss after the three cycles $(430.8 \mathrm{~m}$ of wheel track) was $152.7 \pm 1.9 \mathrm{~mm}^{3}$. These results showed the possibility of using the $\mathrm{Fe} 13 \mathrm{Cr}$ coating for components, where the abrasion resistance is required. The use of $\mathrm{Zn} 15 \mathrm{Al}$ coatings for abrasion worn components is not recommended. 


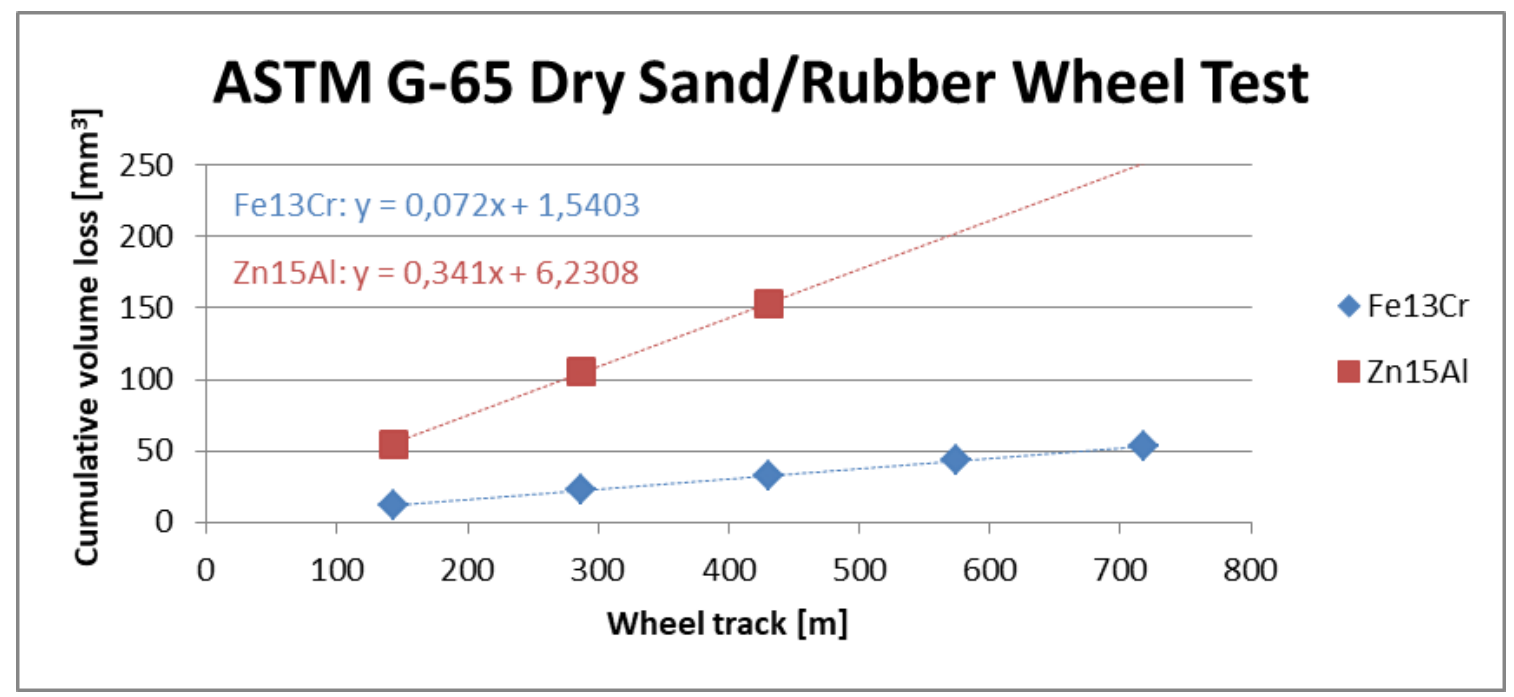

Figure 4 Results of Dry Sand/Rubber Wheel Test

The results of the Erosion Resistance test for Fe13Cr and Zn15Al coatings are shown in Figure 5. The Zn15Al coating had surprised a better erosion resistance than Fe13Cr coating. The dependence of volume loss per angle of impaction is different for each material. For $\mathrm{Zn15Al}$, the volume loss was increasing with a decreasing angle of impaction. This dependence is typical for tough materials because the wear mechanism of tough materials is characterized by plastic deformation, in which the extruded material is removed or the material is cut out by particles of the erosive medium. The dependence of volume loss per angle of impaction for $\mathrm{Fe} 13 \mathrm{Cr}$ coating is slightly decreasing with decreasing angle because in the case of brittle materials, the material is removed due to the formation and intersection of cracks that extend from the point of impact of the particle. The values of volume loss are very low for both materials. The highest volume loss per 2 minutes of intensive actuation of the erosive medium is just $3 \pm 1.4 \mathrm{~mm}^{3}$, therefore both of these materials can be recommended for applications where the erosion resistance is required, such as walkable footplate for example.

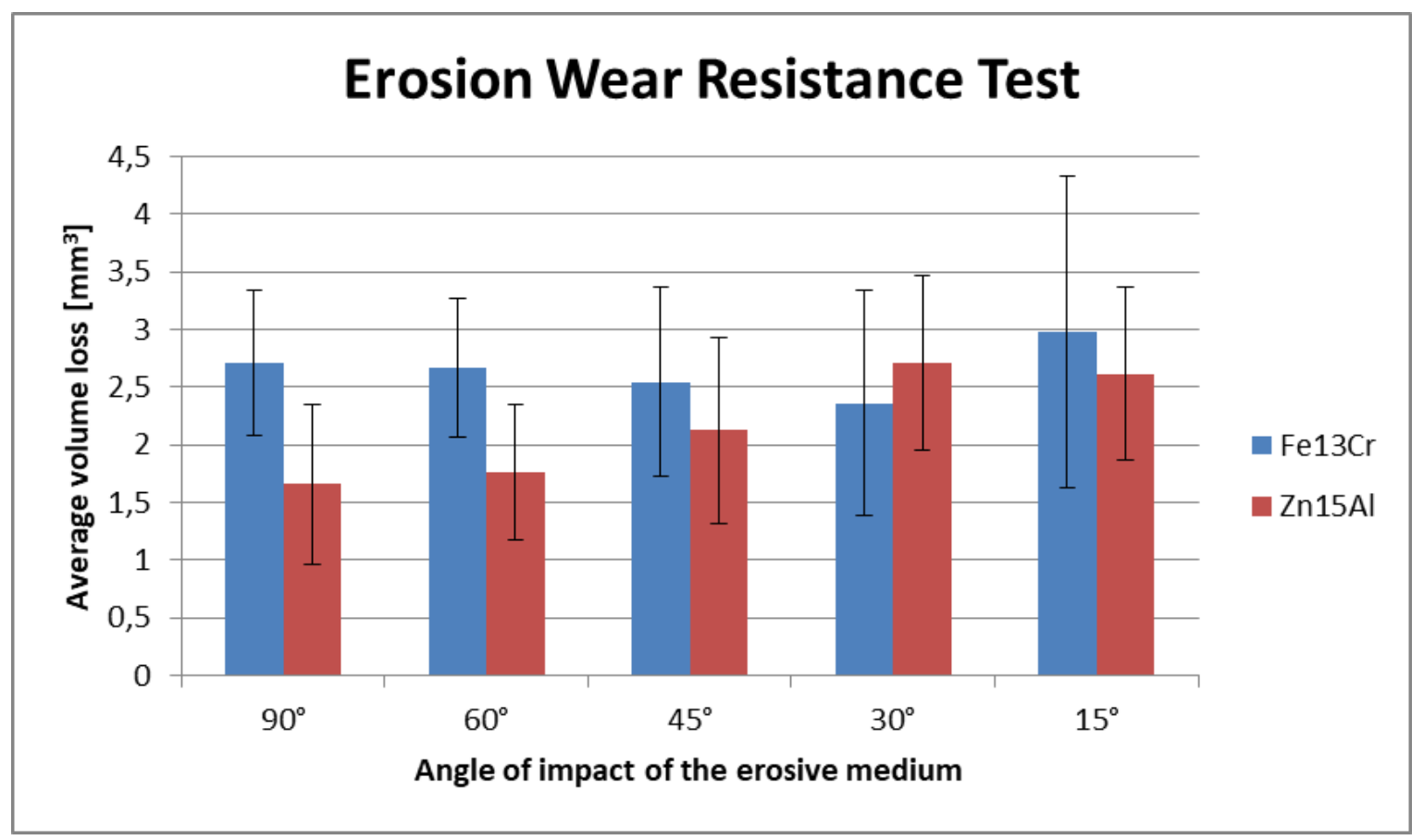

Figure 5 Results of Erosion Wear Resistance Test 


\section{CONCLUSION}

In this paper, the portion of results focused on TWAS technology from the project "Increasing of resistance of rail vehicles components by the means of modern thermal spraying technologies" is presented. Three materials of coating are evaluated. These materials are pure molybdenum, Fe13Cr, and $\mathrm{Zn15Al}$. The ball on flat test was done on molybdenum coating. The results of this test showed very good sliding properties and wear resistance. The mechanical properties of $\mathrm{Fe} 13 \mathrm{Cr}$ and $\mathrm{Zn} 15 \mathrm{Al}$ coatings were evaluated on the Dry Sand/Rubber Wheel Test and on Erosion Wear Resistance Test. The results showed a good erosion wear resistance for both of these materials and also a good abrasion resistance for Fe13Cr coating in contrast with Zn15Al, which had very poor resistance to abrasive wear. The spraying of walkable footplate by materials $\mathrm{Fe} 13 \mathrm{Cr}$ and $\mathrm{Zn} 15 \mathrm{Al}$ are also shortly presented in this paper.

\section{ACKNOWLEDGEMENTS}

The paper has originated in the framework of the solution of project number FV40165 "Increasing of resistance of rail vehicles components by the means of modern thermal spraying technologies".

\section{REFERENCES}

[1] DAVIS, J.. Handbook of Thermal Spray Technology. Materials Park, OH, USA: ASM International, 2004.

[2] FLAME SPRAY TECHNOLOGIES. Wires, thermal spray consuable guide, Netherlands, 2020, Available from https://www.fst.nl/thermal-spray-material/thermal-spray-wires/.

[3] OERLIKON METCO, DSMTS-0010.6 Pure Zinc and Zinc Alloy Thermal Spray Wires (EN), USA, 2016 https://www.oerlikon.com/metco/en/products-services/coating-materials/coating-materials-thermal-spray/wires/ .

[4] BUSHAN, B. Introduction to Tribology, John Wiley \& Sons, Inc., New York, 2002.

[5] ASTM G133-05(2016), Standard Test Method for Linearly Reciprocating Ball-on-Flat Sliding Wear, ASTM International, West Conshohocken, PA, 2016, Available from www.astm.org.

[6] LEGOUX, J-G., ARSENAULT, B., HAWTHORNE H., IMMARIGEON, J-P.. Erosion behavior of WC-10CO-4Cr HVOF Coatings, Thermal Spray Technology, ASM International, USA, 2003, p.405-410.

[7] HAYASHI, N., KAGIMOTO, Y., NOTOMI, A., TAKEDA, Y., KATO, K..Development of new testing method by centrifugal erosion tester at elevated temperature, Wear, 2005.

[8] ASTM G65-16e1, Standard Test Method for Measuring Abrasion Using the Dry Sand/Rubber Wheel Apparatus, ASTM International, West Conshohocken, PA, 2016, Available from www.astm.org.

[9] HOUDKOVÁ, Š., ANTOŠ, J., ŠULCOVÁ, P., LENCOVÁ, K., HAJŠMAN, J., BURDOVÁ, K., DULIŠKOVIČ, J. Comprarison of Mo coatings, deposited by different thermal spray techniques. In Local Mechanical Properties 2019, Prague. 